\title{
Seção Especial-Tradução
}

\section{Formação Profissional no e para o Serviço Público na Alemanha}

\author{
LUDGER SCHRAPPER \\ President of the University of Public Administration of Nordrhein-Westfalen (FHOV). \\ KATRIN MÖLTGEN \\ Professora da Escola Superior de Administração Pública de Nordrhein-Westfalen.
}

SUMÁRIO: Introdução; 1 Bases do serviço público na Alemanha; 2 Vias de recrutamento e formação para o serviço público na Alemanha; 3 A formação para o cargo administrativo elevado nas escolas superiores técnicas do serviço público; 4 A formação profissional na FHöV NRW; 5 Cursos de mestrados no nível de pós-graduação; Conclusão e perspectivas; Referências.

\section{INTRODUÇÃOO}

Ao passo que a crítica à administração pública na Alemanha não quer emudecer, pode-se observar, em outros continentes, um interesse crescente pela estrutura e pelos procedimentos da administração pública na República Federal da Alemanha. Apesar de numerosas deficiências, como, e.g., as esboçadas por diversas comissões de reforma (cf., p. ex., Ministério do Interior do estado da Renânia do Norte-Vestfália 2003) ou as que se apresentam em comparação com o resto da Europa no tocante à qualidade da prestação de serviços (cf. Naschold/Bogumil, 2000), a República Federal da Alemanha é considerada, desde sua existência, um país especialmente bem administrado. Nesse aspecto, principalmente as universidades dos chamados países do BRICS mostram-se interessadas na formação profissional no e para o serviço público na Alemanha, a qual é, então, garante de uma boa administração que, sobretudo, funciona legitimamente.

A seguir ficará claro que, nesse contexto, é atribuído um significado especial à formação profissional para os cargos elevados da administração pública, considerados a "espinha dorsal da administração". Para tanto, serão esboçadas primeiramente algumas bases do serviço público na Alemanha e serão elucidadas as vias de recrutamento e de formação para o serviço público nesse país. Em seguida será apresentada a formação profissional para os cargos elevados do serviço público nas escolas superiores técnicas do serviço público, sendo dada especial atenção à formação na Escola Superior Técnica para a Administração Pública do Estado da Renânia do Norte-Vestfália (doravante, FHöV NRW). Ademais, serão demonstradas possibilidades para uma qualificação continuada.

O seguinte artigo é baseado em diversas publicações e palestras do Doutor Ludger Schrapper, presidente da FHöD NRW (cf. Schrapper 2008; Schrapper 
2011), assim como em uma palestra da Doutora Katrin Möltgen, professora da FHöD NRW, em abril de 2012 em Brasília (Brasil), por ocasião da introdução de um novo curso de mestrado no Instituto Brasiliense de Direito Público, novo parceiro de cooperação da FHöD NRW.

\section{BASES DO SERVIÇO PÚBLICO NA ALEMANHA}

Por "serviço público" entendem-se na Alemanha, sobretudo, os empregados dos órgãos de poder, ou seja, da União, dos 16 estados e das unidades locais (municípios), diferenciadas em comunidades, cidades e distritos. A isso se acrescem os titulares da chamada administração pública indireta, que também desempenham tarefas de poder público, sendo, porém, juridicamente autônomos. Podem ser citados aqui, por exemplo, os titulares da previdência social, a Agência Federal de Empregos e, recentemente, também as universidades. Não são (mais) considerados integrantes do serviço público na Alemanha os grandes prestadores de serviço de infraestrutura, ou seja, ferrovia, correios e telecomunicação. No geral, verifica-se que, no nível internacional, os termos "serviço público" ou "setor público" não podem ser automaticamente equiparados (cf. sobre as imprecisões das conceitualidades também Prümm, 2009, p. 160).

No assim definido "serviço público", trabalham atualmente na República Federal da Alemanha (ano de referência 2010) quase 4,6 milhões de pessoas, entre as quais 53,8\% são mulheres. Com isso, 11,3\% de toda a população ativa é empregada nesse setor. Em comparação com o resto da Europa, esta percentagem se encontra em um nível mais baixo. Os gastos alemães com o serviço público correspondem a 7,4\% do produto interno bruto, os da Dinamarca, encabeçando a lista, 19,7\%. Há 20 anos, após a reunificação da Alemanha, ainda havia mais pessoas empregadas no serviço público alemão - aproximadamente 6,7 milhões de pessoas. O retrocesso se explica, por um lado, pela já mencionada privatização dos correios e da ferrovia, mas, por outro, também por uma considerável redução de pessoal, em especial nos últimos 10-12 anos (cf. também Röber, 2011, p. 15 e ss.).

Diferenciando-se pelos níveis da estrutura tripartite do Estado, tem-se como resultado um número de 457.000 empregados na União (entre eles 185.000 militares de carreira e soldados inscritos por prazo determinado); a isso se acrescentam 45.000 empregados da Bundeseisenbahnvermögen ${ }^{1}$ ( $v$. menção anterior). Nos estados, computamos 1.940.000, nos municípios 1.300.000 funcionários. Por fim, há de se mencionar, ainda, os titulares da administração pública indireta, que conta com um efetivo de aproximadamente 850.000 empregados.

1 A Bundeseisenbahnvermögen é uma entidade da República Federal da Alemanha criada pela Lei de Reorganização das Ferrovias de 1993, responsável pelos antigos funcionários da Deutsche Bundesbahn e da Deutsche Reichsbahn [nota do tradutor]. 
A área da atividade estatal mais rica em recursos humanos é, em primeiro lugar, o setor de educação (escolas e universidades), seguido pelas áreas da proteção social e do setor que serve à garantia da segurança interna e externa. Somente no setor de educação trabalham pouco mais de 1,2 milhão de pessoas, entre estas mais de 1 milhão como empregados no nível dos estados. Isto reflete, por um lado, a distribuição das competências na estrutura federativa alemã. Por outro lado, comprova a extensão do engajamento estatal quando se verifica que aproximadamente apenas $8 \%$ dos alunos de escolas e $4 \%$ dos estudantes universitários estudam em instituições de ensino privadas (cf. Departamento Federal de Estatística 2010).

Os 4,6 milhões de empregados do serviço público trabalham em todos os domínios dos quadros profissionais de uma sociedade moderna, do militar de carreira à enfermeira, da jurista ao eletricista. Se observarmos mais precisamente os diversos grupos profissionais, têm-se como resultado, em parte, clusters pouco surpreendentes como, por exemplo, a parcela desproporcionalmente maior de mulheres no âmbito da educação. Em aspectos de gênero encontram-se também, todavia, desenvolvimentos surpreendentes, entre estes o rápido aumento da quota de mulheres na polícia para, nesse ínterim, aproximadamente $20 \%$. No caso de agrupamentos por especialização, chama a atenção, em uma comparação mundial, a tradicionalmente grande parcela de juristas alemães em funções de liderança na administração pública.

Conhecemos na Alemanha não apenas um status de empregado do setor público; ao contrário, podemos diferenciar - como também no Brasil - dois grupos profissionais:

- Há, primeiramente, os chamados funcionários ou empregados sujeitos às regras de um contrato coletivo de trabalho que, como qualquer funcionário no setor privado, exercem sua função com base em contratos de trabalho segundo as leis do Direito Privado. As condições de trabalho (pagamento, horário de trabalho, férias etc.) são regulamentadas, principalmente, com base em acordos coletivos entre os sindicatos e os empregadores (princípio da autonomia dos parceiros sociais).

- Junto desses, encontramos como especificidade do serviço público o grupo dos servidores públicos. De acordo com o art. $33, \S 4^{\circ}$, da Lei Fundamental e as leis do funcionalismo público que a concretiza (a respeito, Battis, 2009, p. 101 e ss.), a eles está reservada a realização das tarefas de poder público. Seus vínculos empregatícios não são regulamentados por contratos individuais e coletivos, e sim unilateralmente por lei. Eles se encontram numa especial relação de fidelidade com o poder hierárquico (não: empregador), gozam de uma situação de emprego permanente, mas tampouco podem fazer greve para melhoria de suas condições de trabalho. Sua proteção em caso de doença e idade (previdência social) baseia-se em 
sistemas especiais financiados através de impostos e separados da previdência social de todos os demais trabalhadores, alimentada pelas contribuições previdenciárias.

Essa é a teoria. Na prática, encontramos entrementes uma ampla aproximação das condições de emprego de ambos os grupos estatutários. Se há 25 anos o trabalho a tempo parcial pelos servidores públicos se constituía quase que em uma violação da Lei Fundamental, uma vez que a atividade como profissão principal e a plena dedicação ao poder hierárquico representam um elemento estrutural do status de servidor público, hoje, segundo a evolução ulterior do entendimento constitucional, as regulamentações estão completamente equiparadas ao âmbito dos funcionários. Inversamente, entrementes, os funcionários gozam igualmente de fato de uma situação de emprego permanente. E no quotidiano do serviço público o cidadão não consegue distinguir se seu pedido de licença de construção ou a expedição de seu passaporte foram processados por um servidor público ou por um funcionário. Tampouco pode saber com certeza se a professora de seus filhos é uma servidora pública ou não. Sob uma perspectiva externa, isto não soa necessariamente muito lógico (cf. também Bull, 2006, p. 22 e ss.).

O serviço público na Alemanha é estruturado hierarquicamente, o que se demonstra, designadamente, em diversas categorias de carreira, de remuneração ou de pagamento. Para o âmbito dos servidores públicos existem tradicionalmente (assim também ainda no estado da Renânia do Norte-Vestfália) quatro categorias de carreira, nas quais, por sua vez, são concentrados cinco a seis níveis de remuneração: o cargo superior, o cargo elevado, o cargo médio e o cargo simples. As respectivas categorias de carreira abrangem diversos quadros profissionais e o ingresso está vinculado a diferentes condições orientadas pelos mesmos:

- O cargo superior, o mais alto nível hierárquico na administração pública, consiste prioritariamente de profissões acadêmicas como juristas, professores universitários, professores de escolas, médicos, engenheiros, economistas etc. Portanto, trata-se, em regra, de cargos de direção. Condição de ingresso é um curso superior em uma universidade ou escola superior técnica, concluído com um diploma de graduação, um exame de Estado ou, recentemente, um mestrado. Tal curso superior pode ser iniciado a princípio com a aptidão geral para realizar estudos universitários. Além das citadas condições de instrução preparatória, dá-se ainda uma formação, na forma do chamado serviço preparatório de pelo menos um ano.

- O cargo elevado abrange funcionários encarregados de seção administrativa e gerentes do campo técnico na administração e no âmbito da polícia. É também designado de "gerenciamento médio". Chega-se ao cargo elevado por meio de um curso superior com ba- 
charelado, geralmente em escola superior técnica. Condição para ingresso no curso em uma escola superior técnica são, pelo menos, doze anos de formação escolar prévia.

- Para ingressar no cargo médio de carreira do serviço público, responsável por procedimentos preparatórios, é necessário o nível médio de ensino e uma formação correspondente na administração, p. ex., para funcionário técnico da administração.

- No cargo simples incluem-se profissões simples como carteiros, guardas etc. Representa a categoria mais inferior de carreira. Base são a conclusão do ensino secundário básico e uma formação profissional. Neste âmbito, praticamente não se empregam mais servidores públicos de fato, apenas funcionários (vide menção anterior).

Concernente às estruturas da utilização e do desenvolvimento de pessoal, o âmbito dos funcionários é juridicamente menos formalizado. Não obstante, é comum transferir, ao menos informalmente, as estruturas de ordem do âmbito do servidor público. A princípio, o pagamento (salário) de funcionários guia-se pelos elementos característicos da atividade exercida, o que, por sua vez, implica em determinadas condições de instrução preparatória, comparáveis ao âmbito dos servidores públicos. Ao todo existem 15 das chamadas categorias salariais, fixadas por acordo coletivo, em que as categorias $9-12$ correspondem ao cargo elevado e as categorias 13 - 15 ao cargo superior. Ademais, funções de alto valor (p. ex., direção de departamento em um ministério) são remuneradas fora do acordo coletivo.

A parcela dos empregados nas diversas categorias de carreira é dependente do nível estatal, do estado e da unidade de organização. Na administração federal, o nível médio é o âmbito mais rico em pessoal com mais de 53\% em 2011, seguido pelo cargo simples (13,5\%) e pelo cargo elevado com quase $20 \%$ (cf. Ministério Federal do Interior 2011, p. 15). No nível dos estados, em contrapartida, o cargo elevado representa a categoria de empregados mais numerosa.

\section{VIAS DE RECRUTAMENTO E FORMAÇÃO PARA O SERVIÇO PÚB LICO NA ALEMANHA}

Para a formação no serviço público é de interesse a observação mais precisa das vias de recrutamento. Por um lado, os empregadores públicos, como também o âmbito privado, recrutam no mercado de trabalho geral. Isto se aplica, sobretudo, ao cargo superior. Uma certa particularidade é válida para juristas e pedagogos, em proporções nitidamente menores para determinadas profissões técnicas. A grande maioria dos juristas e de futuros professores de escolas conclui, após a formação acadêmica em universidades, outro período de formação, chamado de serviço preparatório (ou serviço de estágio), que é organizado e regulamentado pelo Estado (cf. também Reich, 2005, p. 3 e ss.). 
Esse serviço preparatório termina com o grande exame de Estado (ou "segundo exame de Estado"), o qual, por sua vez, é condição (de qualificação) jurídica para o ingresso no cargo superior de servidor público ou da magistratura, mas, simultaneamente, também para a habilitação para a profissão livre de advogado. Porém, o exame de Estado não transmite o direito a um emprego no serviço público; entre os juristas apenas aproximadamente 15\% de todos os graduados tornam-se servidores públicos ou juízes. No entanto, ele cria condições importantes para uma decisão de contratação, as quais permitem renunciar a um sistema de concursos, como é usual em outros países europeus e fora da Europa como obstáculo ao ingresso no serviço público.

Além do recrutamento de pessoal qualificado no mercado de trabalho, apresenta-se como segunda via a contratação daqueles empregados que, após a obtenção da conclusão do ensino secundário, já foram formados por empregadores públicos. Cerca de $5 \%$ dos 4,6 milhões do conjunto de empregados encontram-se em uma relação de formação profissional. Aqui há de se diferenciar a formação profissional geral, segundo o sistema estabelecido na Alemanha, da instrução profissional, também chamada de formação dual, pois atuam em conjunto o empregador formador e a escola profissionalizante (pública). Estamos falando de todo o leque da instrução profissional, desde o técnico em eletrônica industrial até a assistente de consultório odontológico. Atualmente, o setor público ainda forma em alguns âmbitos para além da própria necessidade, assumindo, assim, uma importante função social e política no mercado de trabalho ao dar aos jovens uma perspectiva, desonerar a economia privada dos custos de formação profissional e abastecer o mercado de trabalho com mão de obra jovem especializada.

A isso se junta a formação nas chamadas profissões administrativas, taIhada especificamente para as necessidades do serviço público. São, no nível da instrução profissional, as formações para atividades de secretariado simples a médias. Entretanto, encontramos também, ademais, formações acadêmicas para a categoria de carreira do cargo administrativo elevado, que será à frente descrito mais precisamente. Dele recrutam-se, sobretudo, os chamados funcionários encarregados de seção administrativa, cuja tarefa é a preparação, frequentemente também realização, de decisões constitutivas de direito com efeito interno e externo, mas também assumem funções de liderança no "gerenciamento médio" da administração pública.

\section{A FORMAC̈ÃO PARA O CARGO ADMINISTRATIVO ELEVADO NAS ESCOLAS SUPERIORES TÉCNICAS DO SERVIÇO PÚBLICO}

A formação para o cargo administrativo elevado na Alemanha ocorre atualmente em 36 escolas superiores técnicas do serviço público com aproximadamente 40.000 estudantes. Entidades mantenedoras são geralmente os estados da federação. Contudo, também a União dispõe de uma escola superior 
técnica própria. A maior entre essas instituições de ensino é a FHöV NRW, com quase 7.000 estudantes. Mas, além destas, existem também instituições nitidamente menores, como a escola superior técnica para o sistema judicial do estado da Renânia do Norte-Vestfália, com cerca de 450 estudantes.

Com relação ao campo de atividade e conteúdos da formação profissional existem quatro grupos distintos:

1. Numericamente, o maior grupo é o cargo elevado da polícia. Até a década de 1990, encontrava-se, nos corpos de polícia da União e dos estados, um modelo de três níveis do desenvolvimento de recursos humanos. Somente no segundo nível, o cargo elevado, é que oficiais da polícia eram preparados por meio de um curso nas escolas superiores técnicas do serviço público para assumirem tarefas em nível de liderança. Este modelo é encontrado até hoje em uma parte das polícias estaduais. Outras, entre elas a Renânia do Norte-Vestfália, conhecem já há mais de 10 anos apenas um modelo de dois níveis, o que significa que toda jovem policial e todo jovem policial estuda primeiramente 3 anos em uma escola superior técnica.

2. O segundo grupo principal é constituído pela administração geral, em que se deve diferenciar entre administração estadual e municipal. A administração geral dos órgãos de poder municipais (comunidades, cidades e distritos) prepondera claramente em número, já que os municípios na estrutura federativa do Estado alemão desempenham uma série de funções de execução.

3. O próximo a ser citado é o grande grupo do cargo elevado na administração financeira e fiscal. A formação profissional para esse grupo se baseia de modo especial em diretrizes da lei federal, uma vez que a atividade legislativa fiscal representa uma competência federal.

4. Por fim, há de se citar como numérico e nitidamente menor o grupo das funções não jurisdicionais no sistema judicial. Também aqui, as bases da formação profissional estão regulamentadas por lei federal. A formação se dá, sobretudo, para a carreira de "curador da justiça", ao qual são transferidas na justiça numerosas funções para que as realize autonomamente, por exemplo, em causas de família e sucessões, em processos de execução judicial e insolvência, bem como no registro.

As escolas superiores técnicas do serviço público podem ser qualificadas no uso linguístico internacional por Universities of Applied Sciences, o que ficará claro examinando-se o surgimento e o desenvolvimento dessas instituições de ensino. 
Em meados da década de 1970, registramos na Alemanha uma onda de criações no campo de escolas superiores técnicas do serviço público. Essa onda pode ser entendida no contexto de uma grande reforma no setor da educação, iniciada no final dos anos de 1960, que tinha como objetivo, em parte, uma academização e, com isso, uma revalorização de formações mais fortemente voltadas para o campo profissional (cf. também, Beschorner, 2009, p. 60 e ss.). Impelido pelas reflexões de uma comissão de reforma para o futuro do serviço público, iniciada pelo parlamento alemão, a conferência dos ministros dos estados para assuntos internos decidiu transferir esse desenvolvimento rumo a uma academização também para a formação dos servidores públicos da categoria de carreira do cargo elevado (cf. Schreiner, 1979, p. 29 e ss.). Esta primeira fase de criação foi seguida por uma fase de consolidação na década de 1980, marcada pelo esforço por garantia do padrão acadêmico (cf. Pappermann et alii, 1982, p. 276 e ss.). A partir do início da década de 1990 podem ser demonstradas influências perceptíveis da nova escola de política administrativa do New Public Management. Nas escolas superiores técnicas do serviço público veem-se, agora, como reação a uma concepção de administração mais fortemente econômica ou gerencialista (cf. Röber, 2011, p. 17), cada vez mais cursos com nítidos elementos de gestão empresarial em seus currículos. Foram entendidos como componente necessário de uma modernização urgentemente indispensável da administração (cf. a respeito, von Richthofen, 1995, p. 97 e ss.). Com relação à durabilidade de tais tendências, pode-se fazer aqui uma observação marginal de que o número dos estudantes no curso de administração de empresas da FHöV NRW caiu pela metade desde o ano letivo 2010/2011. Percebe-se um renascimento dos generalistas da administração com orientação mais jurídica.

A partir de meados dos anos de 1990, sobretudo também como consequência de desenvolvimentos nos estados da antiga Alemanha Oriental após a reunificação alemã, registramos a revivescência de um debate que acompanha de forma latente as escolas superiores técnicas do serviço público desde sua fundação: a exigência por externalização, o que pode ser entendido como transformação em universidades gerais, para alguns também, em "verdadeiras" universidades (cf. von Richthofen, 2007, p. 76 e ss.). Também isso foi concebido como contribuição para uma modernização da administração pública, já que as escolas superiores técnicas da administração são reputadas como as chamadas escolas superiores técnicas internas (Schreiner, 1979, p. 35 e ss.). Em regra elas não possuem um status de entidade, sendo instituições subordinadas dos ministérios setoriais, sejam eles ministérios dos assuntos internos, das finanças ou da justiça. Embora disponham geralmente de uma regulamentação estatutária garantida por lei e de uma garantia de liberdade de ensino e pesquisa, o exercício de tal regulamentação estatutária depende frequentemente de autorização. Restrições são válidas parcialmente também para a autonomia em matéria de pessoal. Entrementes, vários estados transferiram, total ou parcialmente, seus cursos de administração para universidades externas ou - como Berlim - fundiram universidades externas e internas. Ainda não se desenvolveu, até agora, 
uma tendência geral de comportamento (?), talvez porque a formação em administração nas universidades externas ainda não tenha fornecido evidências de uma maior capacidade de desempenho e melhores conclusões (Berthel, 2009, p. 53 e ss. com outras referências; criticamente contra, cf. Röber, 2011, p. 23).

A fase de desenvolvimento atual, aproximadamente desde meados dos anos 2000, é cunhada pelas reformas de Bolonha. No ponto de partida desse processo estava, em 1999, o desejo dos governos europeus em complementar a realização do mercado interno europeu por meio de um "mercado de educação" europeu, o espaço europeu de ensino superior uniforme. A visão era uma comparabilidade das conclusões de curso com a introdução de conclusões escalonadas em graus de bacharelado/mestrado e o máximo de flexibilidade durante o estudo. Na Alemanha, as reformas de Bolonha foram atreladas a uma profunda reforma de toda a educação superior. Os objetivos eram uma orientação profissional mais intensa, uma abreviação dos tempos de estudo e uma redução dos "níveis de abandono do ensino" (cf. Kreutz-Gers, 2011, p. 28 e ss.). Fica aqui em aberto a questão se esses objetivos foram alcançados. Uma resposta fundamentada pela metade extrapolaria os limites do presente artigo. Não obstante, pode ser tomado um aspecto que parece ser incontestável. As reformas de Bolonha fomentam o nivelamento da dicotomia do sistema de ensino superior alemão, que parte da diferenciação entre universidades e escolas superiores técnicas. E essa tendência também se irradia sobre as escolas superiores técnicas do serviço público.

\section{A FORMAÇÃO PROFISSIONAL NA FHÖV NRW}

A FHöV NRW é uma instituição do estado da Renânia do Norte-Vestfália, e tem competência no campo de atividade do Ministério para Assuntos Internos e Municipais. Nela são formados servidores públicos da polícia e da administração geral para o cargo elevado da administração não técnica. Atualmente, quase 7.000 estudantes frequentam a FHöV NRW, entre eles aproximadamente 4.500 estudantes para a profissão da polícia.

Como nas outras escolas superiores técnicas do serviço público, condição para o ingresso na FHöV NRW é a aptidão geral para realizar estudos universitários ou doze anos de formação escolar prévia. Além disso, os candidatos têm que possuir, em regra, a nacionalidade alemã ou a de um Estado-membro da União Europeia para que possam ser contratados como "servidores em estágio preparatório". Em casos excepcionais, o curso superior também pode ser feito na condição de funcionário, i.e., deixa de existir o critério de cidadania da União Europeia como condição de contratação.

Na seleção dos estudantes, a FHöV NRW não possui influência alguma. Os estudantes não se matriculam na universidade, e sim são selecionados pelas entidades responsáveis pela formação - entre estas as administrações munici- 
pais, comunais e distritais, a administração estadual e a polícia na Renânia do Norte-Vestfália. Em regra, antes de sua contratação, os estudantes passam por um procedimento no centro de avaliação na respectiva entidade responsável pela formação. De seu poder hierárquico, os estudantes recebem provimentos mensais de quase 1.000 euros.

Além da administração central com sede em Gelsenkirchen, a escola superior técnica dispõe de sete localizações que se estendem por todo o estado da Renânia do Norte-Vestfália e que, designadamente, visa a garantir aos estudantes uma boa acessibilidade à universidade.

Atualmente são ofertados cinco diferentes cursos na FHöV, concluídos com o grau de bacharelado:

- $\quad$ Serviço de caráter executivo na polícia (B.A.)

- Serviço de administração municipal (LL.B.)

- Gestão empresarial para a administração (B.A.)

- Serviço administrativo estatal (LL.B.)

- $\quad$ Seguro de aposentadoria (LL.B.)

O bacharelado dura três anos e é estruturado de forma dual, i.e., é realizado alternando-se estudo teórico na FHöV NRW e fases práticas nas entidades responsáveis pela formação. Os conteúdos e as competências das partes teórica e prática da formação são descritos em módulos completos e módulos parciais, com uma abordagem, em parte, interdisciplinar.

Na parte teórica da formação na FHöV NRW são transmitidos conteúdos do âmbito do Direito (Direito Público e Europeu, Direito Comunal, Direito Administrativo, Direito Social, Direito relativo aos recursos humanos, Direito relativo ao servidor público, leis de polícia e regulamentação etc.), da economia (gerenciamento de pessoal, administração organizacional, gerenciamento da qualidade, gerenciamento financeiro etc.) e das ciências sociais (ciência política, sociologia, psicologia, ética). As matérias relativas ao Direito preponderam em todos os cursos, apesar de a parcela das diversas disciplinas científicas nos cursos ser diferente. Ela está orientada pela atividade posterior, dependendo em menor extensão das possibilidades de escolha dos estudantes. Assim, por exemplo, no curso de gestão empresarial para a administração encontramos nitidamente mais matérias de economia do que em outros cursos, pois após a conclusão do curso os graduados devem estar em condições de, p. ex., realizarem atividades de controlling. No âmbito da polícia existe, além disso, uma particularidade: aqui o estudo e a prática são complementados por treinamentos específicos (por exemplo, exercícios de tiro) junto ao departamento estadual para formação, aperfeiçoamento e questões de pessoal da polícia da Renânia do Norte-Vestfália. 
Tal como em outras universidades, a transmissão dos conteúdos se dá, em grande parte, em aulas e seminários. Todavia, as aulas, também chamadas de cursos, realizam-se por meio de atividades fixas em sala de aula de aproximadamente 30 estudantes. Uma vantagem essencial consiste no fato de ser fomentado tanto o contato entre professores e estudantes quanto os contatos dos estudantes entre si mesmos, o que, no geral, tem efeito positivo sobre as condições de aprendizagem (disponível em: <http://www.fhoev.nrw.de/studienformen. html>, acesso em: 11 maio 2012). Os seminários servem ao aprofundamento de conteúdos específicos e são realizados em grupos de 12-16 estudantes. Os citados cursos presenciais são complementados pela "autoaprendizagem dirigida", no qual os estudantes têm que explorar ou aprofundar temas. A autoaprendizagem dirigida é auxiliada por uma plataforma de aprendizagem.

A estreita relação com o campo profissional do estudo na FHöV é produzida por meio de duas outras formas de cursos: a realização de projetos e o treinamento de competências sociais. No campo da realização de projetos,

problemas oriundos da prática são examinados com base em conhecimentos científicos e com o auxílio de métodos científicos, e são desenvolvidas possibilidades de soluções. Nisso, um grupo de trabalho do projeto, constituído por estudantes, trabalha autonomamente durante várias semanas - assessorados por acompanhantes do projeto da FHöV ou por representantes da prática - e apresenta, ao fim, um projeto escrito, cujos resultados podem ser aplicados na prática. (Disponível em: <http://www.fhoev.nrw.de/studienformen.html>. Acesso em: 11 maio 2012)

Objetivo do treinamento de competências sociais é a aplicação dos conhecimentos técnico-teóricos adquiridos a determinadas situações apoiadas na prática profissional, bem como a ampliação do próprio repertório comportamental profissional (cf. id.). Para tanto, são realizados com os estudantes treinamentos intensivos durante vários dias, nos quais estes têm a possibilidade de treinar situações concretas do quotidiano profissional, p. ex. em simulações, exercícios e apresentações. Os treinamentos são feitos em pequenos grupos e são acompanhados por dois treinadores.

A qualidade e a relação com o campo profissional das diferentes formas de cursos são garantidas pelos professores e docentes da FHöV, os quais, além de sua qualificação científica, têm que dispor de uma "experiência profissional correspondente", ou seja, frequentemente já tiveram atuação própria em uma administração ou na polícia. Atualmente, encontram-se empregados na FHöV, em tempo integral, aproximadamente 200 professores e docentes. A estes se acrescem numerosos docentes que têm, em regra, uma ocupação principal na administração ou na polícia.

Com a entrega do trabalho de bacharelado, a assim chamada tese, e a conclusão bem-sucedida do colóquio, os estudantes obtêm sua graduação no bacharelado. 


\section{CURSOS DE MESTRADOS NO NÍVEL DE PÓS-GRADUAÇÃo}

Após a conclusão do curso superior para o cargo elevado da administração, os estudantes podem seguir um curso de mestrado, o qual lhes possibilitará o acesso ao cargo superior. Pré-requisito é, geralmente, um bacharelado avaliado na nota geral com uma nota melhor que "satisfatório" e uma atividade profissional de um a dois anos na administração após a conclusão do primeiro ciclo do ensino superior.

Atualmente, diversas universidades oferecem, em cooperação com a FHöV NRW, cursos de mestrado no nível de pós-graduação, dirigidos especialmente a graduados da FHöV NRW e de outras escolas superiores técnicas do serviço público.

O curso de pós-graduação em "Gestão pública", da Universidade de Kassel, que confere ao estudante o título de Master of Public Administration (MPA), dirige-se a profissionais especializados que planejam, realizam e analisam processos de reforma na administração pública. No âmbito do curso serão transmitidas as capacidades correspondentes para a configuração efetiva e eficiente de processos de desempenho. O curso contém ao todo 11 módulos, que abrangem desde "marketing administrativo e e-Government", passando por "gestão e liderança de pessoal", até "globalização e política administrativa", ou seja, estão orientados preferencialmente para a gestão empresarial. Outro componente do curso é um semestre de prática (disponível em: <http://www.mpa. uni-kassel.de/de/studium.asp>, acesso em: 11 maio 2012). Além de poucas aulas presenciais, o curso é organizado essencialmente por meio de uma plataforma na Internet, na qual são disponibilizados materiais para o aprendizado, são proferidas palestras on line, mas também são realizados testes e avaliações.

O curso de pós-graduação paralelo à atividade profissional "Human Ressource Management" na Universidade de Bochum abrange quatro semestres e foi concebido para profissionais especializados e executivos no âmbito de recursos humanos de empresas comerciais e administrações. Isto também se reflete nos módulos que abrangem todos os campos de ação de uma gestão moderna de pessoal. Objetivo do mestrado é servir, por um lado, ao aprofundamento dos conhecimentos e à aquisição de um novo know-how, mas também transmitir competências de ação, bem como otimizar e treinar capacidades pessoais (disponível em: <http://www.akademie.rub.de/weiterbildung/masterstudiengang_human_ressource_management.shtml>, acesso em: 11 maio 2012).

O título de Master of Business Administration (MBA) pode ser obtido por estudantes do curso de mestrado em "Gestão empresarial para o New Public Management", oferecido pela escola superior técnica de Dortmund em cooperação com a FHöV NRW, com participação do Instituto para Estudos Integrados (disponível em: <http://www.fh-dortmund.de/de/studi/fb/9/studieng/990/ 
start_bfn.php>, acesso em: 11 maio 2012). "Servidores públicos e funcionários na administração pública ou em uma organização sem fins lucrativos, que aspiram a uma posição de liderança superior ou querem ampliá-la e desejam adquirir a competência social e econômica para tanto necessária" (id.), são citados como grupo-alvo preferencial. Além de competências técnicas administrativas e jurídicas, são transmitidas competências sociais e metodológicas em 16 módulos no total. Assim como na Universidade de Kassel, uma plataforma na modalidade de e-Learning constitui a base para modernas formas de ensino e aprendizagem (cf. $i d$.).

Ademais, a partir de setembro de 2013, a FHöV oferecerá um curso próprio de mestrado em "Public Management", direcionado a (futuros) executivos na administração pública. Nesse mestrado, serão aprofundadas e especializadas as competências jurídicas, administrativas e sociais adquiridas durante o bacharelado, necessárias aos executivos. Comparativamente ao primeiro ciclo do ensino superior, as ciências sociais terão uma participação maior, pois o conhecimento das condições básicas políticas e sociais da ação administrativa se constitui em pré-requisito essencial para adaptar futuros desenvolvimentos e desafios da administração e considerá-los no quadro das decisões de gestão. Também será dada especial importância ao desenvolvimento de competências pessoais e sociais no âmbito do curso, já que é condição essencial para um bom posto de liderança. O mestrado será realizado paralelamente à atividade profissional e, portanto, ocorrerá em grande parte na modalidade de autoaprendizagem. As aulas presenciais na FHöV serão realizadas à noite ou nos finais de semana. O corpo docente será formado por professores e docentes da FHöV.

\section{CONCLUSÃO E PERSPECTINAS}

Parece legítimo o interesse de universidades estrangeiras pela formação no serviço público na Alemanha. Assim estão claramente definidas as condições de ingresso para uma atividade no serviço público na República Federal da Alemanha, oferecendo este múltiplas possibilidades de formação profissional.

Como ficou claro a partir do exemplo da formação profissional para o cargo elevado na administração, são transmitidas, no âmbito da formação, as competências específicas e sociais necessárias para a categoria de carreira. Estas são, além de um know-how jurídico fundamentado, cujo objetivo é garantir a ação legítima dos funcionários, conhecimentos na área das ciências econômicas e sociais. Por um lado, estes são imprescindíveis com vistas à qualidade da prestação de serviços e à orientação por parte da administração orientada para o cliente; por outro, são condição necessária para se relacionar de forma competente com cidadãos de diferentes contextos culturais. A formação generalista do bacharelado oferece, ademais, uma boa base para uma qualificação 
continuada e especialização no campo de diversos cursos de mestrado para a atividade na administração pública.

Não obstante a avaliação fundamentalmente positiva, a formação atual no serviço público vem caracterizada por diversos desafios.

Um desses desafios consiste em assegurar e ampliar os padrões universitários alcançados na formação profissional para o serviço público. Há riscos na tendência em aumentar, de forma alheia à universidade, a influência dos ministérios de inspeção sobre os conteúdos e a organização do ensino. Exemplos são encontrados nos estados da Baixa-Saxônia e de Hamburgo, onde as escolas superiores técnicas da polícia e da administração financeira foram rebaixadas ao nível de "academias" (de forma crítica, Wagner, 2009, p. 194 e ss.). Este procedimento coloca em dúvida os desenvolvimentos dos últimos 40 anos. Mais do que nunca, um moderno serviço público orientado para o cidadão não necessita apenas de um sólido know-how de aplicação e experiência, mas também da capacidade para autovisão e reflexão críticas, bem como para a recepção de novas ideias e tendências, em outras palavras: "solucionadores de problemas no lugar de artesãos" (Berthel, 2009, p. 56).

Outro desafio diz respeito não apenas às escolas superiores técnicas administrativas, e sim a todo o serviço público na Alemanha. Este desafio se chama "desenvolvimento demográfico", e é caracterizado por uma diminuição da população, um envelhecimento da sociedade e uma crescente "multiculturalização". Como consequência, baixa o potencial de população ativa na Alemanha e aumenta a concorrência entre empregadores privados e públicos por candidatos qualificados. Uma resposta a esses desafios toma por base essencialmente uma oferta atraente de formação profissional para os jovens. E tal oferta deve contemplar a possibilidade de qualificação continuada e de aprendizagem vitalícia paralela à atividade profissional. Especialmente por isso, a FHöV NRW oferecerá, no mais tardar em 2013, cursos próprios de aperfeiçoamento profissional para o âmbito da administração pública. Porém, uma resposta aos desafios esboçados se baseia, sobretudo, em preservar a capacidade de ação do Estado, por meio da consolidação dos orçamentos públicos, e em elaborar uma estratégia global concisa na relação com o desenvolvimento demográfico (cf. a respeito, Möltgen, 2010).

\section{REFERÊNCIAS}

BATTIS, Ulrich. Bundesbeamtengesetz. Munique, 2009.

BERTHEL, Ralph. Das Studium an einer internen Fachhochschule im Spannungsfeld zwischen theoretischem Anspruch und den Erwartungen der Praxis. In: BÖNDERS, Thomas et al. (ed.). Kompetenz und Verantwortung in der Bundesverwaltung. Munique, 2009.

BESCHORNER, Fritz. Zur Entwicklung und Struktur der Fachhochschulen. In: BÖNDERS, Thomas et al. (ed.). Kompetenz und Verantwortung in der Bundesverwaltung. Munique, 2009. 
BULL, Hans Peter. Vom Staatsdiener zum öffentlichen Dienstleister. Zur Zukunft des Dienstrechts. Berlim, 2006.

Bundesministerium des Innern [Ministério Federal do Interior]. Der öffentliche Dienst des Bundes. Daten zur Personalstruktur 2011. Disponível em: <http://www.bmi. bund.de/SharedDocs/Downloads/DE/Broschueren/2011/personalstruktur.pdf? blob=publicationFile>. Acesso em: 11 maio 2012.

Innenministerium des Landes Nordrhein-Westfalen [Ministério do Interior do estado da Renânia do Norte-Vestfália] (ed.). Zukunft des öffentlichen Dienstes, -öffentlicher Dienst der Zukunft. Relatório da comissão instituída pelo governo do estado da Renânia do NorteVestfália. Düsseldorf, 2003.

KREUTZ-GERS, Waltraud. Herausforderung Bologna: Berufsqualifizierung durch Hochschulstudium - Idee und Wirklichkeit. In: SCHRAPPER, Ludger (ed.). Ausbildung für die öffentliche Verwaltung - Zur Zukunft des öffentlichen Dienstes als Arbeitgeber. BadenBaden, 2011.

MÖLTGEN, Katrin. Veränderungsbedarfe im Personalmanagement öffentlicher Verwaltungen vor dem Hintergrund des demografischen Wandels. In: STEMBER, Jürgen Eixelsberger, Wolfgang (ed.). Verwaltung im Wandel. Neue Anforderungen des modernen Verwaltungsmanagements in Mitteleuropa. Berlim, 2010.

NASCHOLD, Frieder/Bogumil, Jörg. Modernisierung des Staates. New public management in Deutscher und internationaler Perspektive. 2. ed. Opladen, 2000.

PAPPERMANN, Ernst; FRECHEN, Stefan; KAUTHER, Helmut; PIPPKE, Wolfgang; ROTERS, Wolfgang. Zur Bewährung der Ausbildung an den Fachhochschulen des öffentlichen Dienstes. Regensburg, 1982.

REICH, Andreas. Die beschäftigungsrechtliche Gestaltung des Vorbereitungsdienstes bei der Reform der Juristenausbildung. RiA, p. 3, 2005.

RÖBER, Manfred. Ausbildung für die öffentliche Verwaltung und Zukunft des öffentlichen Dienstes als Arbeitgeber - Erwartungen der Gesellschaft und Forderungen der Beschäftigten. In: SCHRAPPER, Ludger (ed.). Ausbildung für die öffentliche Verwaltung - Zur Zukunft des öffentlichen Dienstes als Arbeitgeber. Baden-Baden, 2011.

PRÜMM, Hans Paul. Braucht die öffentliche Verwaltung eine eigene akademische Grundausbildung? In: BÖNDERS, Thomas, et al. (ed.). Kompetenz und Verantwortung in der Bundesverwaltung. Munique, 2009.

SCHRAPPER, Ludger (ed.). Ausbildung für die öffentliche Verwaltung - Zur Zukunft des öffentlichen Dienstes als Arbeitgeber. Baden-Baden, 2011.

. Der Bachelor kommt. p. 257, apf 2008.

SCHREINER, Alois. Der gehobene Dienst in der Verwaltungs- und Bildungspolitik. In: KÖNIG, Klaus (ed.). Ausbildung für den gehobenen Dienst. Baden-Baden, 1979.

STATISTISCHES Bundesamt. Personal des öffentlichen Dienstes, 2010.

VON RICHTHOFEN, Dieprand. Reform der Verwaltung - Reform von Aus- und Fortbildung? In: BEHRENS, Fritz et al. (ed.). Den Staat neu denken. Reformperspektiven für die Landesverwaltungen. Berlim, 1995. Von der Behörde zur Hochschule. Gelsenkirchen, 2007.

WAGNER, Karl. Entwicklungen und Perspektiven - Wohin führt der Weg der Fachhochschulen für den öffentlichen Dienst. In: BÖNDERS, Thomas et al. (ed.). Kompetenz und Verantwortung in der Bundesverwaltung. Munique, 2009. 


\section{SIIES}

$<$ http://www.akademie.rub.de> $<$ http://www.fh-dortmund.de>

$<$ http://www.fhoev.nrw>

$<$ http://www.mpa.uni-kassel.de> 